\title{
A Common Fixed Point Theorem for Two Hybrid Pairs of Mappings in $b$-Metric Spaces
}

\author{
K. P. R. Rao ${ }^{1}$ and K. R. K. Rao ${ }^{2}$ \\ ${ }^{1}$ Department of Mathematics, Acharya Nagarjuna University, Nagarjuna Nagar 522 510, India \\ ${ }^{2}$ Department of Mathematics, Vignana Bharathi Institute of Technology, Aushapur, Ghatkesar, Hyderabad 501 301, India
}

Correspondence should be addressed to K. P. R. Rao; kprrao2004@yahoo.com

Received 25 January 2013; Accepted 17 March 2013

Academic Editor: Jens Lorenz

Copyright (c) 2013 K. P. R. Rao and K. R. K. Rao. This is an open access article distributed under the Creative Commons Attribution License, which permits unrestricted use, distribution, and reproduction in any medium, provided the original work is properly cited.

We introduce a condition (W.C.C) and prove a common fixed point theorem for two hybrid pairs of mappings in $b$-metric spaces.

\section{Introduction and Preliminaries}

The study of fixed points for set-valued contraction maps using the Hausdorff metric was initiated by Nadler [1] in 1969, who extended the Banach contraction principle to set-valued mappings. The theory of set-valued maps has many applications in control theory, convex optimization, differential equations, and economics.

Recently Amini-Harandi [2] proved a set-valued version of Ciric's [3] theorem as follows.

Theorem 1. Let $(X, d)$ be a complete metric space. Suppose $T$ : $X \rightarrow C B(X)$ satisfy

$$
\begin{gathered}
H(T x, T y) \leq q \max \{d(x, y), d(x, T x), d(y, T y), \\
d(x, T y), d(y, T x)\},
\end{gathered}
$$

for all $x, y \in X$, where $0 \leq q<1 / 2$. Then $T$ has a fixed point in $X$.

Aydi et al. [4] proved a slight version of the above theorem in $b$-metric spaces as follows.

Theorem 2. Let $(X, d)$ be a complete b-metric space. Suppose $T: X \rightarrow C B(X)$ satisfy

$$
\begin{gathered}
H(T x, T y) \leq q \max \{d(x, y), d(x, T x), d(y, T y), \\
d(x, T y), d(y, T x)\},
\end{gathered}
$$

for all $x, y \in X$, where $0 \leq q<1 /\left(s^{2}+s\right)$. Then $T$ has a fixed point in $X$.

In this paper, we introduce a new condition, namely, "condition (W.C.C)" of mappings which are not continuous and non commuting pairwise. Using this new condition we prove a common fixed point theorem for two pairs of hybrid mappings in $b$-metric spaces.

For the sequel, we need the following concepts.

Czerwik [5] presented a generalization of the well-known Banach fixed point theorem in $b$-metric spaces by defining the following.

Definition 3. Let $X$ be a nonempty set and $s \geq 1$ a given real number. A function $d: X \times X \rightarrow \mathbb{R}^{+}$is called a $b$-metric if the following axioms are satisfied for all $x, y, z \in X$ :

$$
\begin{aligned}
& \left(b_{1}\right) d(x, y)=0 \text { if and only if } x=y, \\
& \left(b_{2}\right) d(x, y)=d(y, x), \\
& \left(b_{3}\right) d(x, y) \leq s[d(x, z)+d(z, y)] .
\end{aligned}
$$

Let $(X, d)$ be a $b$-metric space. Let $\mathrm{CB}(X)$ be the collection of all non-empty closed and bounded subsets of $X$. For $A, B \in$ $\mathrm{CB}(X)$, define

$$
H(A, B)=\max \{\delta(A, B), \delta(B, A)\},
$$


where

$$
\begin{aligned}
& \delta(A, B)=\sup \{d(a, B): a \in A\}, \\
& \delta(B, A)=\sup \{d(b, A): b \in B\},
\end{aligned}
$$

with

$$
d(a, B)=\inf \{d(a, b): b \in B\}
$$

Then $H$ is called the Hausdorff metric induced by the $b$ metric.

We cite the following lemmas from Czerwik [6]. For more details we refer to $[7,8]$.

Lemma 4. Let $(X, d)$ be a b-metric space. For any $A, B, C \in$ $C B(X)$ and any $x, y \in X$, we have the following:

(i) $d(x, B) \leq d(x, b)$ for any $b \in B$,

(ii) $\delta(A, B) \leq H(A, B)$,

(iii) $d(x, B) \leq H(A, B)$ for any $x \in A$,

(iv) $H(A, A)=0$,

(v) $H(A, B)=H(B, A)$,

(vi) $H(A, C) \leq s[H(A, B)+H(B, C)]$,

(vii) $d(x, A) \leq s[d(x, y)+d(y, A)]$.

Lemma 5. Let $(X, d)$ be a b-metric space. Let $A, B \in C B(X)$. Then for each $\epsilon>0$ and for all $b \in B$ there exists $a \in A$ such that $d(a, b) \leq H(A, B)+\epsilon$.

Lemma 6. Let $(X, d)$ be a b-metric space. For $A \in C B(X)$ and $x \in X$, we have $d(x, A)=0 \Leftrightarrow x \in \bar{A}=A$.

In this paper, we introduce the following condition on three mappings without continuity and commutativity (W.C.C).

Definition 7. Let $(X, d)$ be a $b$-metric space. The mappings $(f, g ; S)$ where $f, g: X \rightarrow X$ and $S: X \rightarrow \mathrm{CB}(X)$ are said to satisfy the condition (W.C.C) if $d(f x, g y) \leq d(y, S x)$ for all $x, y \in X$.

Remark 8 . The mappings $(f, g ; S)$ satisfying the condition (W.C.C) need not be continuous and commutative in view of the following examples.

Example 9. Let $(X, d)$ be a $b$-metric space, where $X=[0,1]$ and $d(x, y)=|x-y|^{2}$.
Define $f, g, S: X \rightarrow X$ by

$$
f x= \begin{cases}\frac{x}{12} & \text { if } x \in[0,1), \\ \frac{1}{24} & \text { if } x=1,\end{cases}
$$

$$
g x= \begin{cases}\frac{x}{6} & \text { if } x \in[0,1), \\ \frac{1}{12} & \text { if } x=1,\end{cases}
$$

$$
S x= \begin{cases}\frac{x}{2} & \text { if } x \in[0,1), \\ \frac{1}{4} & \text { if } x=1 .\end{cases}
$$

We distinguish the following cases.

Case 1. Consider $0 \leq x<1$ and $0 \leq y<1$

Then $d(f x, g y)=\left|\frac{x}{12}-\frac{y}{6}\right|^{2}=\frac{1}{36}\left|\frac{x}{2}-y\right|^{2}=\frac{1}{36} d(y, S x)$.

Case 2. Consider $0 \leq x<1$ and $y=1$

Then $d(f x, g y)=\left|\frac{x}{12}-\frac{1}{12}\right|^{2}=\frac{1}{36}\left|\frac{1}{2}-\frac{x}{2}\right|^{2}<\frac{1}{36} d(y, S x)$.

Case 3. Consider $x=1$ and $0 \leq y<1$

Then $d(f x, g y)=\left|\frac{1}{24}-\frac{y}{6}\right|^{2}=\frac{1}{36}\left|y-\frac{1}{4}\right|^{2}=\frac{1}{36} d(y, S x)$.

Case 4. Consider $x=1$ and $y=1$

$$
\text { Then } d(f x, g y)=\left|\frac{1}{24}-\frac{1}{12}\right|^{2}=\frac{1}{576}<\frac{9}{16}=d(y, S x) \text {. }
$$

Thus $d(f x, g y) \leq d(y, S x)$ for all $x, y \in X$ is satisfied.

In this example all the mappings are discontinuous.

Example 10. Let $d(x, y)=|x-y|^{2}$ be a $b$-metric on a set $A=$ $\{x, y\}$. Define $f x=f y=y, g x=y, g y=x$, and $S x=S y=x$. Clearly the mappings $(f, g ; S)$ satisfy the condition (W.C.C) and the pairs $(f, g),(f, S)$, and $(g, S)$ are not commuting.

Now, we prove our main result with the condition (W.C.C) for two hybrid pairs of mappings in $b$-metric spaces.

\section{Main Result}

Theorem 11. Let $(X, d)$ be a complete b-metric space. Let $f, g$ : $X \rightarrow X$ and $S, T: X \rightarrow C B(X)$ be mappings satisfying the following: 
(2.1.1) $H(S x, T y) \leq q M(x, y)$, where $M(x, y)=\max \{d(f x$, $g y), d(f x, S x), d(g y, T y), d(f x, T y), d(g y, S x)\}$ for all $x, y \in X$, where $0 \leq q<1 /\left(s^{2}+s\right)$,

(2.1.2) $\bigcup_{x \in X} S x \subseteq g(X)$ and $\bigcup_{x \in X} T x \subseteq f(X)$,

(2.1.3) the mappings $(f, g ; S)$ or the mappings $(f, g ; T)$ satisfy the condition (W.C.C).

Then either the pairs $(f, S)$, and $(g, T)$ have coincidence points or the mappings $S, T, f$ and $g$ have a common fixed point in $X$.

Proof. Suppose $M(x, y)=0$ for some $x, y \in X$.

Then $f x \in S x$ and $g y \in T y$. Thus $x$ is a coincidence point of $f$ and $S$, and $y$ is a coincidence point of $g$ and $T$.

Assume that $M(x, y)>0$ for all $x, y \in X$.

Let $\epsilon=(1 / 2)\left(1 /\left(s^{2}+s\right)-q\right)$ and $\beta=q+\epsilon=(1 / 2)\left(1 /\left(s^{2}+\right.\right.$ s) $+q)$.

Then $\epsilon>0$ and $0<\beta<1$.

Let $x_{0} \in X$. From (2.1.2), there exist $x_{1}, y_{1} \in X$ such that $y_{1}=g x_{1} \in S x_{0}$.

From (2.1.2), there exist $x_{2}, y_{2} \in X$ such that $y_{2}=f x_{2} \in$ $T x_{1}$ and from Lemma 5, we have

$$
\begin{aligned}
d\left(y_{1}, y_{2}\right) & \leq H\left(S x_{0}, T x_{1}\right)+\epsilon M\left(x_{0}, x_{1}\right) \\
& \leq q M\left(x_{0}, x_{1}\right)+\epsilon M\left(x_{0}, x_{1}\right), \\
& =\beta M\left(x_{0}, x_{1}\right) .
\end{aligned}
$$

Again from (2.1.2), there exist $x_{3}, y_{3} \in X$ such that $y_{3}=g x_{3} \in$ $S x_{2}$ and from Lemma 5 , we have

$$
\begin{aligned}
d\left(y_{2}, y_{3}\right) & \leq H\left(S x_{2}, T x_{1}\right)+\epsilon M\left(x_{2}, x_{1}\right) \\
& \leq q M\left(x_{2}, x_{1}\right)+\epsilon M\left(x_{2}, x_{1}\right), \quad \text { from }(2.1 .1) \\
& =\beta M\left(x_{2}, x_{1}\right) .
\end{aligned}
$$

Continuing in this way, we get the sequences $\left\{x_{n}\right\}$ and $\left\{y_{n}\right\}$ in $X$ such that $y_{2 n+1}=g x_{2 n+1} \in S x_{2 n}, y_{2 n+2}=f x_{2 n+2} \in T x_{2 n+1}$ for all $n=0,1,2,3, \ldots$ and

$$
\begin{gathered}
d\left(y_{2 n+1}, y_{2 n}\right) \leq \beta M\left(x_{2 n}, x_{2 n-1}\right), \\
d\left(y_{2 n+1}, y_{2 n+2}\right) \leq \beta M\left(x_{2 n}, x_{2 n+1}\right) \quad \text { for } n=1,2,3, \ldots
\end{gathered}
$$

For simplification, write $d_{n}=d\left(y_{n}, y_{n+1}\right)$.

Now

$$
\begin{aligned}
d_{2 n+1}= & d\left(y_{2 n+1}, y_{2 n+2}\right) \\
\leq & \beta M\left(x_{2 n}, x_{2 n+1}\right) \\
= & \beta \max \left\{d\left(y_{2 n}, y_{2 n+1}\right), d\left(y_{2 n}, y_{2 n+1}\right),\right. \\
& \left.d\left(y_{2 n+1}, y_{2 n+2}\right), d\left(y_{2 n}, y_{2 n+2}\right), 0\right\} \\
\leq & \beta \max \left\{d_{2 n}, d_{2 n+1}, s\left[d_{2 n}+d_{2 n+1}\right]\right\}
\end{aligned}
$$

which in turn yields

$$
d_{2 n+1} \leq \gamma d_{2 n}
$$

where $\gamma=\max \{\beta, s \beta /(1-s \beta)\}$.

Similarly, we can show that

$$
d_{2 n} \leq \gamma d_{2 n-1} .
$$

Thus, from (17) and (18), we have $d_{n} \leq \gamma d_{n-1}$ for all $n=$ $1,2,3, \ldots$, so that

$$
d_{n} \leq \gamma^{n} d_{0} \quad \forall n=1,2,3, \ldots
$$

If $\gamma=\beta$, then $\gamma s=\beta s=(s / 2)\left(1 /\left(s^{2}+s\right)+q\right)<s /\left(s^{2}+s\right)=$ $1 /(s+1) \leq 1 / 2<1$.

If $\gamma=s \beta /(1-s \beta)$, then $\gamma s=s(s \beta /(1-s \beta))<s[1 /(s+$ $1) / 1-1 /(s+1)]=1$.

Thus

$$
\gamma s<1 .
$$

Since $\gamma<1$, from (19), we have

$$
d_{n} \longrightarrow 0 \quad \text { as } n \longrightarrow \infty \text {. }
$$

Now for $m, n \in \mathbb{N}$ with $m>n$, we have

$$
\begin{aligned}
d\left(y_{n}, y_{m}\right) \leq & s d\left(y_{n}, y_{n+1}\right) \\
& +s^{2} d\left(y_{n+1}, y_{n+2}\right)+\cdots+s^{m-n} d\left(y_{m-1}, y_{m}\right) \\
\leq & \left(s \gamma^{n}+s^{2} \gamma^{n+1}+\cdots+s^{m-n} \gamma^{m-1}\right) d_{0}, \text { from } \\
\leq & s \gamma^{n}\left(1+s \gamma+\cdots+s^{m-n-1} \gamma^{m-n-1}+\cdots\right) d_{0} \\
= & \frac{\gamma^{n} s}{1-\gamma s} d_{0} \rightarrow 0 \quad \text { as } n, m \rightarrow \infty .
\end{aligned}
$$

Hence $\left\{y_{n}\right\}$ is a Cauchy sequence in $X$. Since $X$ is complete, there exists $z \in X$ such that $y_{n} \rightarrow z$ which in turn yields $f x_{2 n} \rightarrow z$ and $g x_{2 n+1} \rightarrow z$ as $n \rightarrow \infty$.

Suppose the mappings $(f, g ; S)$ satisfy the condition (W.C.C). Then

$$
d(f x, g y) \leq d(y, S x) \quad \forall x, y \in X .
$$

From (23), we have

$$
d\left(f x_{2 n}, g z\right) \leq d\left(z, S x_{2 n}\right) \leq d\left(z, g x_{2 n+1}\right) .
$$

Letting $n \rightarrow \infty$, we get

$$
d(z, g z) \leq 0 \quad \text { so that } g z=z \text {. }
$$




$$
\begin{aligned}
& \text { Now } \\
& \frac{1}{s} d(z, T z) \\
& \leq d\left(z, g x_{2 n+1}\right)+d\left(g x_{2 n+1}, T z\right) \\
& \leq d\left(z, g x_{2 n+1}\right)+H\left(S x_{2 n}, T z\right) \\
& \leq d\left(z, y_{2 n+1}\right) \\
& \quad+q \max \left\{\begin{array}{c}
d\left(f x_{2 n}, g z\right), d\left(f x_{2 n}, S x_{2 n}\right), d(g z, T z), \\
\quad d\left(f x_{2 n}, T z\right), d\left(g z, S x_{2 n}\right)
\end{array}\right\} \\
& \quad+q \max \left\{\begin{array}{c}
d\left(y_{2 n}, z\right), d\left(y_{2 n}, y_{2 n+1}\right), d(z, T z), \\
d\left(y_{2 n}, T z\right), d\left(z, y_{2 n+1}\right)
\end{array}\right\} .
\end{aligned}
$$

Using (vii) of Lemma 4 and letting $n \rightarrow \infty$ and using (21), we get

$$
\frac{1}{s} d(z, T z) \leq 0+q s d(z, T z) .
$$

Thus we have

$$
d(z, T z) \leq q s^{2} d(z, T z)
$$

so that

$$
d(z, T z)=0 \quad \text { since } q s^{2}<1
$$

From Lemma 6, we have $z \in T z$. Thus

$$
g z=z \in T z
$$

From (23), we get

$$
d(f z, z)=d(f z, g z) \leq d(z, S z)
$$

Now from (2.1.1), we have

$$
\begin{aligned}
d(z, S z) \leq & H(S z, T z) \\
\leq & q \max \{d(f z, g z), d(f z, S z), d(g z, T z) \\
& d(f z, T z), d(g z, S z)\} \\
\leq & q \max \{d(z, S z), s[d(z, S z)+d(z, S z)] \\
& 0, s d(z, S z), d(z, S z)\} \\
\quad \text { from }(30) \text { and }(31) & \\
= & 2 q s d(z, S z) .
\end{aligned}
$$

Hence $z \in S z$, since $2 q s<1$.

From (31), we have $f z=z$. Thus

$$
f z=z \in S z \text {. }
$$

From (30) and (33), it follows that $z$ is a common fixed point of $f, g, S$, and $T$.

\section{Acknowledgment}

The authors are thankful to the referee for his valuable suggestions.

\section{References}

[1] S. B. Nadler Jr., "Multi-valued contraction mappings," Pacific Journal of Mathematics, vol. 30, pp. 475-488, 1969.

[2] A. Amini-Harandi, "Fixed point theory for set-valued quasicontraction maps in metric spaces," Applied Mathematics Letters, vol. 24, no. 11, pp. 1791-1794, 2011.

[3] Lj. B. Ćirić, "A generalization of Banach's contraction principle," Proceedings of the American Mathematical Society, vol. 45, pp. 267-273, 1974.

[4] H. Aydi, M.-F. Bota, E. Karapinar, and S. Mitrovic, "A fixed point theorem for set-valued quasi-contractions in $b$-metric spaces," Fixed Point Theory and Applications, vol. 2012, article 88, 8 pages, 2012.

[5] S. Czerwik, "Contraction mappings in b-metric spaces," Acta Mathematica et Informatica Universitatis Ostraviensis, vol. 1, pp. 5-11, 1993.

[6] S. Czerwik, "Nonlinear set-valued contraction mappings in b-metric spaces," Atti del Seminario Matematico e Fisico dell'Università di Modena, vol. 46, no. 2, pp. 263-276, 1998.

[7] M. Boriceanu, "Strict fixed point theorems for multivalued operators in b-metric spaces," International Journal of Modern Mathematics, vol. 4, no. 3, pp. 285-301, 2009.

[8] M. Boriceanu, "Fixed point theory for multivalued generalized contraction on a set with two b-metrics," Studia. Universitatis Babeş-Bolyai. Mathematica, vol. 54, no. 3, pp. 1-14, 2009. 


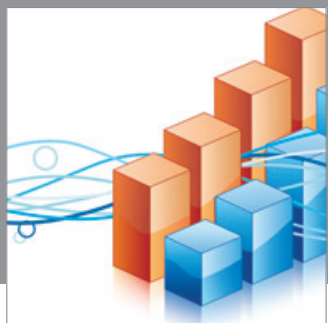

Advances in

Operations Research

mansans

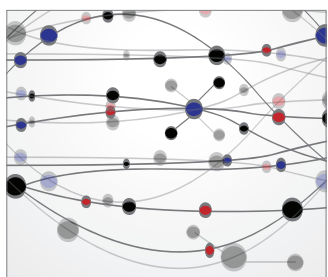

The Scientific World Journal
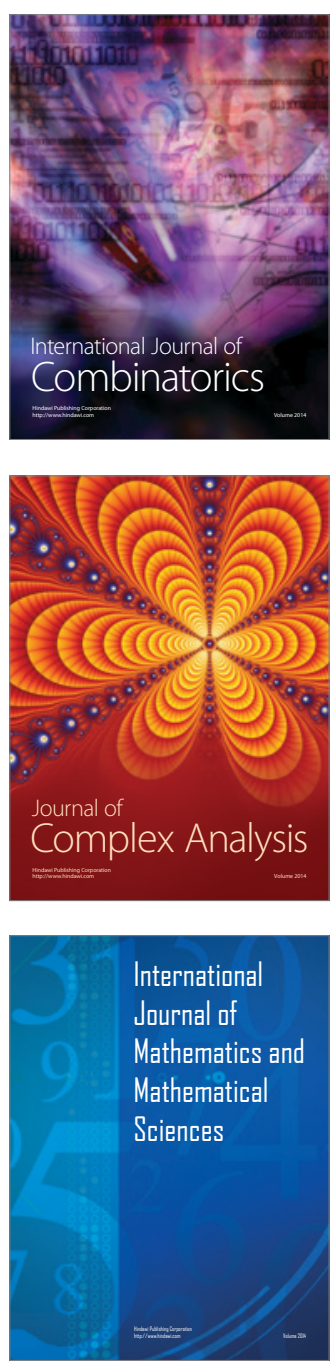
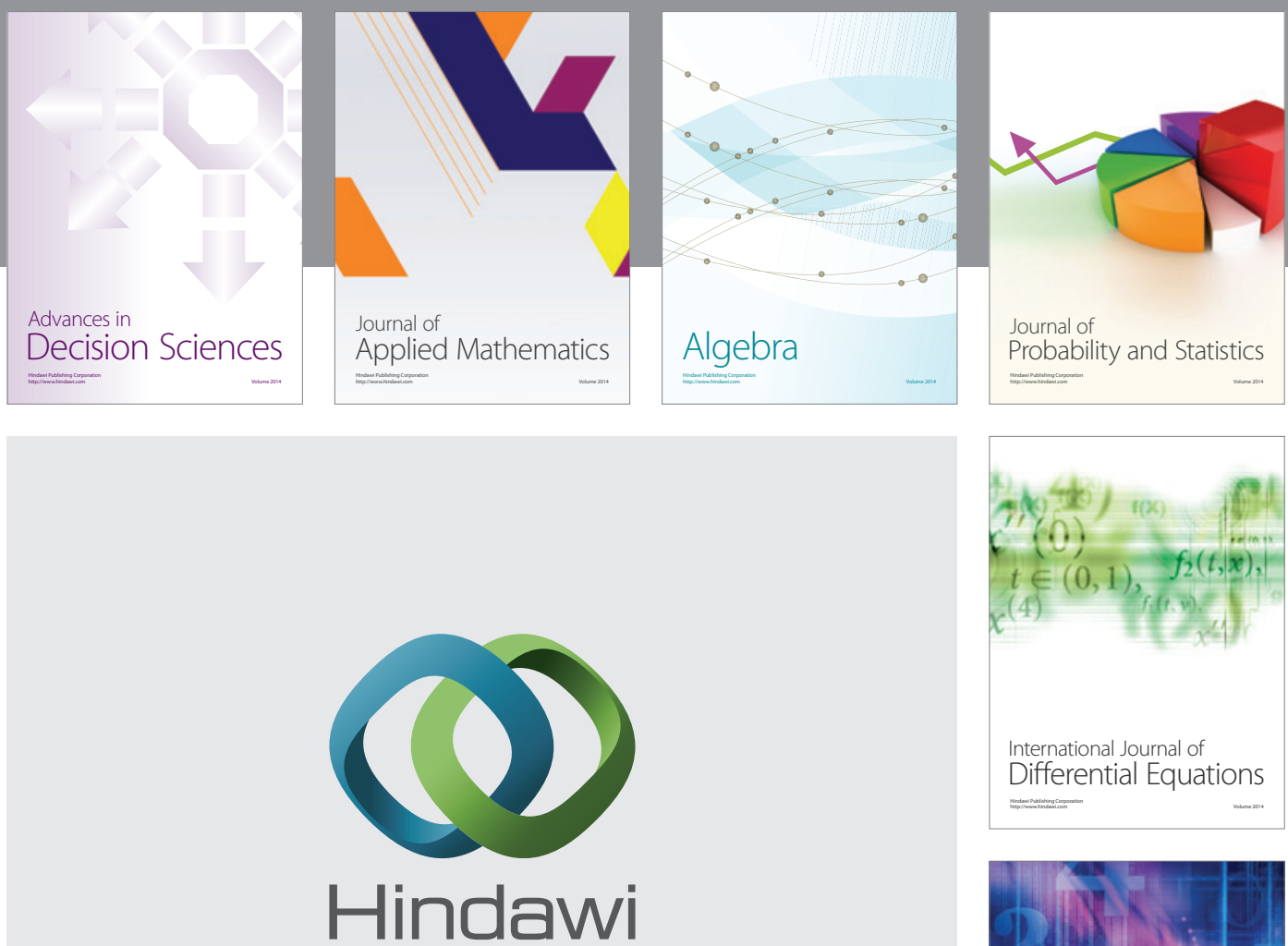

Submit your manuscripts at http://www.hindawi.com
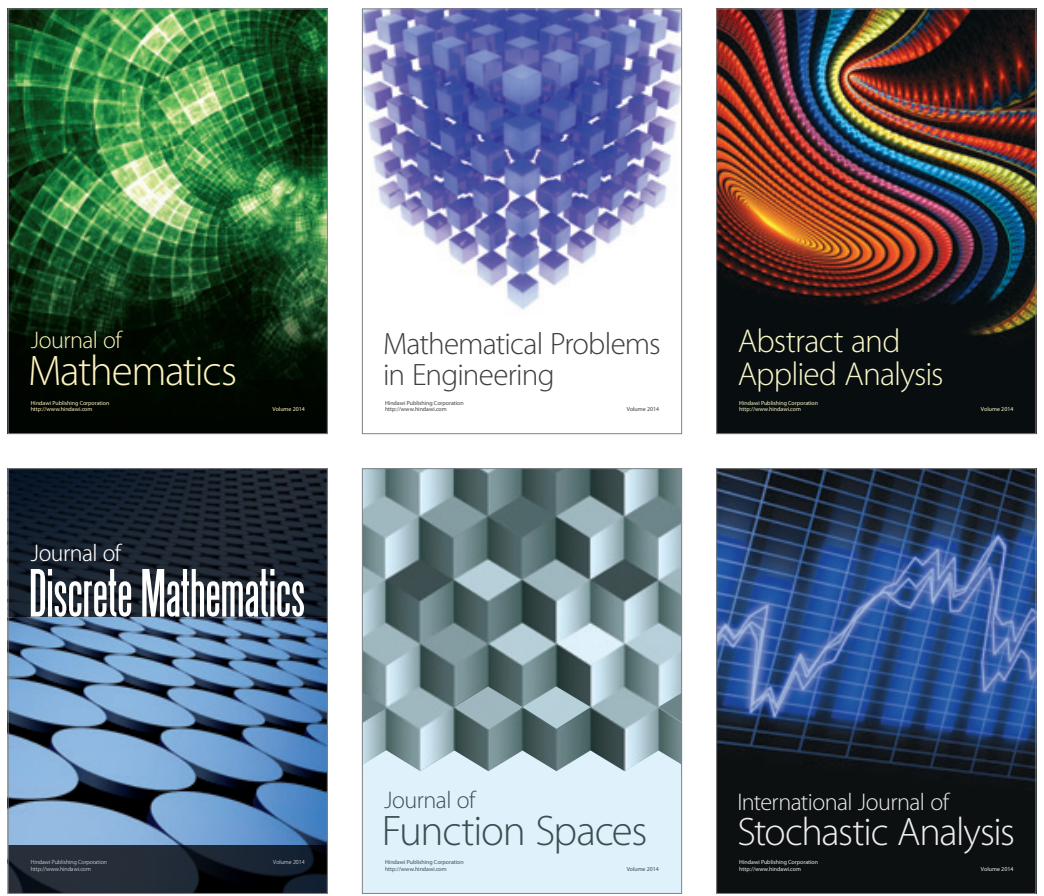

Journal of

Function Spaces

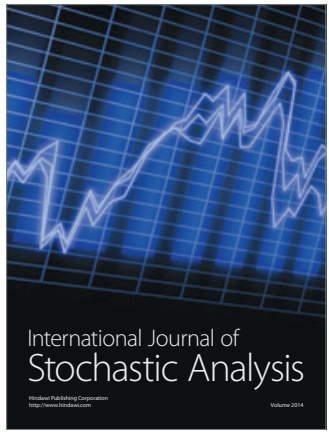

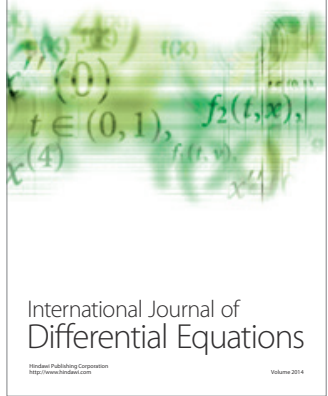
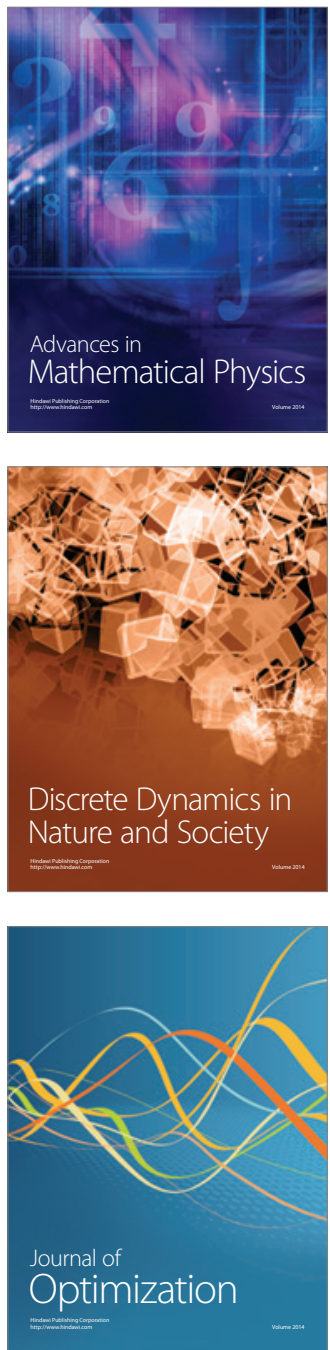